\title{
Social Media and Early Warning Systems for Natural Disasters: A Case Study of Typhoon Etau in Japan
}

\author{
Katsushige Kitazawa ${ }^{\mathrm{a}, \mathrm{b}, *}$, Scott A. Hale $\mathrm{H}^{\mathrm{a}, \mathrm{c}}$ \\ ${ }^{a}$ Oxford Internet Institute, University of Oxford, UK \\ ${ }^{b}$ Sompo Holdings Inc., Japan \\ ${ }^{c}$ Meedan, Inc., San Francisco, USA
}

\begin{abstract}
Due to the significant improvement of disaster-related information, further reduction of disaster risks requires not only governments to provide more scientifically accurate information but also the public to take appropriate action at the correct times. Meanwhile, there is ongoing work to integrate social media into Early Warning Systems (EWSs), but the ecology of social media information during crises remains poorly understood. This study seeks to understand public responses on social media to EWSs using the case of a 2015 typhoon (the Kanto-Tohoku Heavy Rain) in Japan. Using a corpus of 35 million tweets, computational methods such as topic modeling, and geospatial analysis we find that: 1) emergency warnings are likely to have people be more attentive to the warnings but this does not translate to an increased discussion of actions such as evacuation; 2) the expected shift of public attention (from awareness to preparation and then action) seems to happen on social media. Overall, we show that analysis of social media data can compliment traditional survey-based approaches to understand how the public respond to information from Early Warning Systems.
\end{abstract}

Keywords: Early warning systems, Social media, Topic model, typhoon, Japan

2010 MSC: 00-01, 99-00

\section{Introduction}

In the last few decades, the accuracy of weather forecasts has been significantly improved, thanks to satellites, supercomputers, and other technologies. This has led to earlier warnings of some natural disasters and a longer lead-time for people to prepare and take risk-mitigating actions. As a result, the impacts of natural disasters have been reduced in Japan: a generally decreasing trend in the number casualties by all natural disasters can be seen over time from 1963 to 2014. [1].

To reduce disaster risks further, government and meteorological agencies must address a large, remaining challenge: ensuring clear information and encouraging citizens to take appropriate actions in a timely manner.

\footnotetext{
* Corresponding author

Email addresses: kkitazawa1@sompo.io (Katsushige Kitazawa), scott.hale@oii.ox.ac.uk (Scott A. Hale)
} 
In spite of the advanced timing of disaster-related information, the information landscape has become more diverse and complex, and governments are no longer the sole source of authoritative information $[2,3]$. This may make it more difficult for people to connect information to appropriate action-taking. Thus, governments, which usually play a central role in disaster management, have been shifting their focus from improving the accuracy of information to a results-oriented approach in order to narrow the gap between governments and the public [4].

Geertman, Ferreira, and Goodspeed [5] maintain that connecting government information to appropriate and timely public action requires stronger government-public interaction, namely a balance between "publichelp" by governments, "mutual-help" by local communities, and "self-help" by individuals. In practice, most national governments worldwide are currently working on balancing these three factors. For instance, the Japanese government officially promotes Voluntary Organisations for Disaster Prevention (VODPs), which are organisations run by residents that aim to further enhance the self-help and mutual-help disaster risk reduction (DRR) capacity.

\subsection{Disaster stages and social media}

The Internet as not only a broadcast but also as a bidirectional communication platform has a large potential to improve the status quo by connecting governments and the public. Firstly, the Internet has a strong capability of disseminating information directly to individuals in near real-time: a survey by the Ministry of Internal Affairs and Communications in Japan (MAIC) shows that the use of mobile devices and computers in Japan has reached $94.7 \%$ and $73.0 \%$ respectively. This indicates the high accessibility of information in terms of both time and place. In fact, the number of people who used social media as an information collection tool in the 2015 Kumamoto Earthquake had increased forty-fold compared to the 2011 Great East Japan Earthquake. On the other hand, social media also enable peer-to-peer communication among the public, which could enhance mutual-help and self-help capacity, both of which are necessary to further enhance the current DRR capability. In Japan, the number of DRR communities on social media has been increasing, and such online communities greatly helped various local activities after the 2011 Great East Japan Earthquake including evacuation, rescue, and recovery [6].

In general, DDR strategies differ in each stage of a natural disaster. The three principal stages are often before (Preparedness), during (Response), and after (Recovery) a disaster [7]. The DRR-related research follows this classification, and this should be applied to the research on social media use for DRR; however, most research to date has focused on the before and after stages (as discussed further below).

This research explores public responses on social media in the during stage, especially focusing on Early Warning Systems (EWSs), which play a vital role in the during stage by instructing people to take appropriate and timely responses that mitigate risks. EWSs are expected to help deliver information to the right people with the right timing. As represented by the 'virality' of social media meaning a strong peer-to-peer 
information contagion [8], social media platforms have a potential to enhance EWSs given how easily messages can be re-shared and forwarded. Nevertheless, it can be said that the use of social media in the during stage is less popular than the before and after stages. In fact, only $3 \%$ of Japanese citizens used social media to read warnings about typhoon Man-yi in 2013, suggesting the fact that social media is still underutilized as a source of warnings and related information [9]. Of course, reading warnings is only one aspect and other actions not supported by traditional media are arguably more important but under researched. While governments are capable of promoting the public use of social media, disaster-related agencies are still afraid of the possibility of inaccurate information of "dubious provenance" [10]; so, it is important to understand the online information environment during natural disasters in order for disaster-related agencies to make best use of social media platforms.

\subsection{Early Warning Systems}

Traditionally, the function of warnings for natural disasters was merely to inform people about the likelihood of natural hazards such as heavy rain, gusts, storm surge, and so on, from a scientific perspective. However, the significant improvement of weather forecasts and development of telecommunication technologies including mobile phones and the Internet has largely widened the role of warnings, which have been shifting to include a social component. This new class of warnings comprise Early Warning Systems (EWSs). While traditional warnings aim to provide more accurate forecasts, the goal of EWSs is result-oriented, leading people to take appropriate and timely actions without confusion and hesitation [11]. To achieve this, the basic strategies of EWSs have been widely discussed around the globe. The United Nations Office for Disaster Risk Reduction (UNDRR), for instance, developed two indispensable factors the EWSs should include: 'end-to-end' and 'people-centred.'

First, end-to-end refers to the goal of having EWSs as integrated systems that cover all the components leading to appropriate and timely public actions. Mukhtar [12] proposed the following classification of the components included in end-to-end EWSs: 1) Risk knowledge, 2) Monitoring and warning services, 3) Dissemination and communication, and 4) Response capacity. Unlike traditional warnings which have solely a single component, EWSs include even education about how to respond to warnings, for example. Nevertheless, Garcia \& Fearnley [13] found that official organisations worked independently in the case of the 2010 Tsunami in Hawaii and demonstrated that, although each component is individually sufficient, the links between the components are still weak. They also emphasised that inter-organisational collaboration is required to tackle this challenge.

Second, EWSs also must be "people-centric", that is, they require strong public involvement. As mentioned above, unlike traditional warnings, EWSs aim for 'appropriate and timely public responses,' rather than merely disseminating warnings. This indicates that, while governments are responsible for providing sufficient infrastructure, individuals and local communities need to respond in a timely and appropriate manner, 
for example, learning beforehand what to do in an emergency situation. Moreover, Baudoin \& Wolde-Georgis [14] emphasised that, to make EWSs operationally successful, the communication gap between national and local players needs be narrowed. For example, the citizens need to fully understand what each warning means and what they should do in response to those warnings, and governments should take the responsibility of providing education opportunities to support this. Otherwise, even sophisticated disaster information system developed by governments can be meaningless.

\subsection{Operational EWS in Japan}

To incorporate these factors with the current operational warnings, the Japan Meteorological Agency (JMA) operates a stage-based warning system consisting of advisories, warnings, and emergency warnings. Each stage expects municipalities and the public to respond in a different way as shown Figure 1. For instance, in response to the warnings, the public is expected to shift their responses in a timely manner including: 1) Awareness (Advisory): to collect disaster related information (e.g., weather forecasts, tropical cyclone information, Radar/Nowcast) and to pay attention to any updates, 2) Preparation(Warning): to stay away from dangerous areas (e.g., river flood planes, steep cliffs) and to prepare for evacuation if a catastrophe becomes likely, and 3) Action (Emergency Warning): to take immediate action for self-protection when a catastrophe is highly likely to occur. Strictly speaking, appropriate action and its timing depends on the exact conditions of each person. For instance, the disabled and elderly need to evacuate at an earlier stage because it might take longer time to move to a safe place.

Offline public responses to the EWS in Japan has been widely investigated. The Japanese government, mainly the Cabinet Office and the Japan Meteorological Agency (JMA), organise a committee to review the impact of the EWS in actual disaster cases. Also, the media often discuss the possibility of improving the current EWS. In more academic venues, survey research has been done. For instance, Ushiyama [15] conducted a questionnaire survey about how people acted in response to emergency warning during a heavy rain that occurred in the western part of Japan in 2018. He founded that, although $80 \%$ of people in the most-affected regions recognised the issuance of an emergency warning, only $20 \%$ cancelled plans to be outside of their homes, meaning that the disaster warnings did not change people's actions in many cases.

\section{Research questions}

As mentioned above, Early Warning Systems are designed to help people to shift their attention/actions appropriately in a timely manner when a disaster is likely to occur. Some research has already surveyed the connection between Japan's EWS and public responses, but this has not been confirmed online, especially on social media. In fact, little research has even attempted to investigate the use of online data during a disaster to under people's responses to EWS warnings. Therefore, this article aims to analyse how public 


\section{Examples of municipal and resident responses to weather Warnings/Advisories}

\begin{tabular}{|c|c|c|c|c|c|c|c|c|}
\hline & \multicolumn{8}{|c|}{ Weather Warning/Advisory type } \\
\hline & \multicolumn{3}{|c|}{ Heavy rain } & \multirow[b]{2}{*}{ Storm } & \multirow{2}{*}{$\begin{array}{l}\text { Storm } \\
\text { surge }\end{array}$} & \multirow{2}{*}{$\begin{array}{c}\text { High } \\
\text { waves }\end{array}$} & \multirow{2}{*}{$\begin{array}{l}\text { Heavy } \\
\text { snow }\end{array}$} & \multirow[b]{2}{*}{ Snowstorm } \\
\hline & & $\begin{array}{l}\text { Sediment } \\
\text { incident }\end{array}$ & Inundation & & & & & \\
\hline \begin{tabular}{|l|} 
Emergency \\
Warning \\
(Significant \\
likelihood of \\
catastrophe)
\end{tabular} & 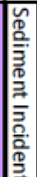 & $\begin{array}{c}\text { Heavy rain } \\
\text { Emergency } \\
\text { Warning } \\
\text { (sediment } \\
\text { incident) }\end{array}$ & $\begin{array}{l}\text { Heavy rain } \\
\text { Emergency } \\
\text { Warning } \\
\text { (inundation) }\end{array}$ & $\begin{array}{c}\text { Storm } \\
\text { Emergency } \\
\text { Warning }\end{array}$ & $\begin{array}{c}\text { Storm } \\
\text { surge } \\
\text { Emergency } \\
\text { Warning }\end{array}$ & $\begin{array}{c}\text { High wave } \\
\text { Emergency } \\
\text { Warning }\end{array}$ & $\begin{array}{c}\text { Heavy } \\
\text { snow } \\
\text { Emergency } \\
\text { Warning }\end{array}$ & $\begin{array}{c}\text { Snowstorm } \\
\text { Emergency } \\
\text { Warning }\end{array}$ \\
\hline $\begin{array}{l}\text { Warning } \\
\text { (Chance of } \\
\text { catastrophe) }\end{array}$ & $\frac{1}{7}$ & $\begin{array}{l}\text { Heavy rain } \\
\text { Warning } \\
\text { (sediment } \\
\text { incident) }\end{array}$ & $\begin{array}{l}\text { Heavy rain } \\
\text { Warning } \\
\text { (inundation) }\end{array}$ & $\begin{array}{c}\text { Storm } \\
\text { Warning }\end{array}$ & $\begin{array}{c}\text { Storm } \\
\text { surge } \\
\text { Warning }\end{array}$ & $\begin{array}{c}\text { High wave } \\
\text { Warning }\end{array}$ & $\begin{array}{l}\text { Heavy } \\
\text { snow } \\
\text { Warning }\end{array}$ & $\begin{array}{c}\text { Snowstorm } \\
\text { Warning }\end{array}$ \\
\hline \begin{tabular}{|l} 
Advisory \\
(Possible \\
development \\
of serious \\
adverse \\
conditions) \\
\end{tabular} & & Heavy rain $\mathrm{A}$ & dvisory & $\begin{array}{c}\text { Gale } \\
\text { Advisory }\end{array}$ & $\begin{array}{c}\text { Storm } \\
\text { surge } \\
\text { Advisory }\end{array}$ & $\begin{array}{c}\text { High waves } \\
\text { Advisory }\end{array}$ & $\begin{array}{c}\text { Heavy } \\
\text { snow } \\
\text { Advisory }\end{array}$ & $\begin{array}{c}\text { Snowstorm } \\
\text { Advisory }\end{array}$ \\
\hline
\end{tabular}

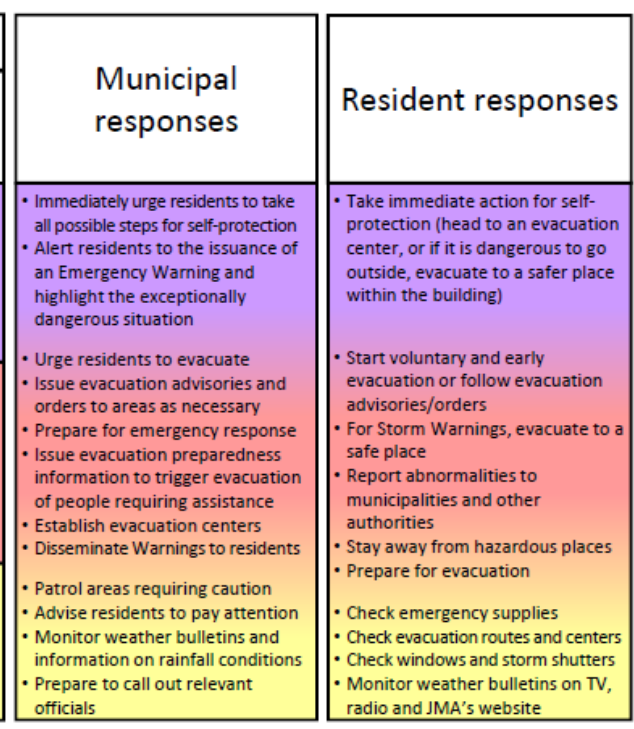

Figure 1: Examples municipal and resident responses to weather warnings/advisories (Retrieved from https://www.jma.go.jp/ jma/en/Emergency_Warning/examples_of_responses)

attention and discussion on social media are effected by the issuance of warnings and emergency warnings using the case of Typhoon Etau (Typhoon 1518), which struck Japan in 2015.

We specifically address three research questions. First, how does the issuance of an emergency warning affect public attention/discussion towards action-taking on social media? Second, in what ways does online public attention/discussion in response to warnings compare with what is expected within Japan's EWS framework? Third, what effect does the issuance of an emergency warning have to public attention/discussion on social media?

While various DRR activities have taken place, many still think that disasters are someone else's issue, leading to a delay in actions such as evacuation and, at worse, an increase in casualties. To change this situation, the result-oriented EWS in Japan aims to make sure that people continuously shift their attention phase by phase in response to disaster-related information including warnings and evacuation instructions. Hence, people can avoid the situation that they are forced to take very last minute actions. It is not possible to directly measure the actions of the public currently, and this research will therefore examine how public attention shifts on social media in response to warnings. This is clearly not a perfect proxy, but the survey techniques asking about how people acted (or would act) used in much other research are also limited by recall bias and other factors [16]. Taken alongside survey research, social media analysis provides a complementary lens. One advantage of social media is the exact time information attached to messages: we use these timestamps to analyse the speed of the public response to the issuance of emergency warnings. 
Disaster-related agencies would like people to respond as quickly as possible to warnings to further reduce risk.

In the next section, relevant literature will be introduced with a focus on government and public interaction on social media, as well as social media crisis responses. Then, the methods and data for this study will be explained. Finally, the results will be presented and discussed.

\section{Literature review}

\subsection{Government-public interactions on social media}

Understanding disaster-related communication requires consideration of the strong role of central governments. While various information sources in general are available, governments are still influential in crisis information networks. In detail, the information from governmental services such as warnings and associated instructions, in many cases, triggers public conversations when a disaster is likely to happen [17]. It is difficult for citizens to forecast hazardous weather on their own, and hence most people rely heavily on the information from governments to plan their actions. Moreover, no organisations and individuals, except the Japan Meteorological Agency (JMA), are allowed to issue warnings in Japan in order to keep a consistent and clear message, a principle known as 'Single Voice' [18]. In this way, an authoritarian approach is still dominant in warning dissemination.

On the other hand, the Internet has the potential to change the role of governments in societal information networks [2]. Research on the role of governments in information networks is a long-standing topic in public policy and politics offline, and discussion about the impact of the Internet on the landscape is popular. Linders [19], for instance, maintains that the emergence of Web 2.0 has changed the interaction between governments and public, from "passive-consumption" to "coproduction." Moreover, Escher et al. [20] developed a method to computationally measure nodality, an index indicating "the extent to which government is at the centre of social and informational networks."

The impact of social media on information networks could be particularly large in disaster management, where an authoritarian approach used to be dominant, and much research has attempted to examine the unknown ecology of online information networks related to disasters. Sutton et al. [21] investigated an inter-organisational collaboration on social media in a crisis and demonstrated from their Twitter analysis during the Deepwater Horizon 2010 oil spill disaster that governments, especially federal governments, tend to dominate the main topics during the disaster with active, directed conversations. Sutton et al. [22] focused on the public officials on Twitter during the Waldo Canyon wildfire in order to help them to establish Twitterbased warnings. Specifically, they examined the elements that relate to the behavioural activity on Twitter, including thematic contents and message styles. Moreover, Mauroner and Heudorfer [23] demonstrated that social media during crises promotes individual responses, leading to more effective collective actions such as 
voluntarily activities. Nevertheless, little research has been carried out to understand public responses to government information as a natural disaster unfolds, especially in the early stages when a disaster is likely to occur but has not happened yet.

\subsection{What makes people respond on social media?}

There are two main incentives for people to generate or (re-)share information on social media during crises: sharing anxiety and warning others. On the one hand, Miura et al. [24] demonstrated that the content relating to anxiety is more likely than the content relating to angry and positive emotion (e.g., comfort) to be propagated on Twitter shortly after disasters by conducting a sentiment analysis for the tweet dataset collected during the Great East Japan Earthquake.

One the other hand, social media exert an element of social influence and can make it more likely for people to take action [25]. Retweets of breaking news, photos of what is happening, and statements of what actions people are taking could encourage others to also take action [26]. This in turn can enhance the potential of social media to harness public-centric warning dissemination capacity of EWSs. One typical case is that the information about local events promotes people to regard the disaster as a self issue, more than traditional media which broadcast general information. Nevertheless, little research has examined public crisis responses in terms of warning each other. Therefore, an investigation of this warning nature is important to promote the implementation of social media in EWSs.

\subsection{Why Twitter?}

Unlike traditional media, social media can enable more two-way communication. This enables mutual-help among the public such as warning each other, exchanging important information, and integrating knowledge. However, social media can also lead to negative consequences in crises. To make best use of social media and avoid adverse consequences, the information ecology on social media should be better understood by governments, technology firms, and local communities. To support this, it is necessary to investigate "what is happening' on social media in crises at the very beginning.

While various social media platforms have been researched, Twitter is the most popular platform for social media analysis because of its data accessibility. While Twitter has been over-researched in many contexts (see [27]), Twitter is specifically appropriate for disaster-related information in Japan, the location of this study, due to the following three characteristics of Twitter:

- Volume: Twitter is one of the most popular social media platforms in Japan, and the number of users is still growing. Japanese is the second-most represented language on the platform [28], and the number of active users in Japan reached 45 million in 2017, representing approximately 35\% of the population. In contrast, Facebook has only 27 million users in the country. LINE is another popular platform, but data is generally not available due to its end-to-end encryption. 
- Speed: Twitter has a capacity to spread information more rapidly than other platforms. Bright [29] found that $50 \%$ of the shares of a news article on Twitter happened in the first hour after its publication, while Facebook and GooglePlus took two hours to reach 50\%. The timeline on Twitter is continuously updated in near real-time manner, and the retweet functionality acts as an amplifier of messages [22]. Since decisions are expected to be made in a limited time during disasters, the speed at which information propagates is key for effective, timely communication.

- Simplicity: Each message (tweet) on the platform is simple with no more than 140 (Japanese) characters and, possibly, the inclusion of links, photos, and/or videos. ${ }^{1}$ As a result, messages can be sent rather quickly and generally each message addresses a limited number of topics.

Of course, however, care must be taken when interpreting the analysis as Twitter is only one of several platforms that are used in Japan. Future research should analyse the extent to which interaction dynamics on other platforms resemble those on Twitter [30].

\section{Data and methods}

\subsection{Data Preparation}

Twitter has multiple public APIs. The search API provides only a "sampling of recent Tweets published in the past 7 days" and "is focused on relevance and not completeness" (emphasis in the original). ${ }^{2}$ In contrast, the streaming API provides tweets in near real-time as they occur, but it is not available for non-space separated languages such as Japanese. ${ }^{3}$. Therefore, we used a dataset created with snowball sampling by Jin, Toyoda, \& Yoshinaga [31]. Starting with tracking all tweets from 26 famous Japanese users, they expanded the collection of tweets to include all tweets by active users retweeting/mentioned by these users. The data was collected via the statuses/user_timeline API endpoint and spans a period of more than six years with more than 5 million tweets each day, including a large proportion of active Japanese users.

Using this dataset, we filtered tweets using a keyword-based approach to identify disaster-related tweets. Special care was taken to avoid words that have not only disaster-related senses but also non-disaster related senses such as wind (風).

Our specific case is that of Typhoon Etau, which struck the eastern part of Japan on September 2015, resulting in a disaster known as the "Kanto-Tohoku Heavy Rain" after the names of the most affected regions (Figure 2). A tropical cyclone generated near Guam on 2 September evolved into Typhoon Etau

\footnotetext{
${ }^{1}$ While messages can now be longer in other languages, the limit remains 140 characters for Japanese and a few other languages.

${ }^{2}$ https://developer.twitter.com/en/docs/tweets/search/overview/standard

${ }^{3}$ https://developer.twitter.com/en/docs/tweets/filter-realtime/guides/basic-stream-parameters\#track
} 
on 3 September. Etau gradually approached Japan, and made landfall in Aichi Prefecture on 9 September. Moving over the Eastern part of Japan, it produced an Akisame front (an autumn rain front), and caused a heavy rain in the Kanto and Tohoku regions. In particular, emergency warnings for heavy rain were issued in three prefectures: Miyagi, Tochigi, and Ibaraki. Eight people were killed, and more than 12,000 houses were flooded in the disaster.

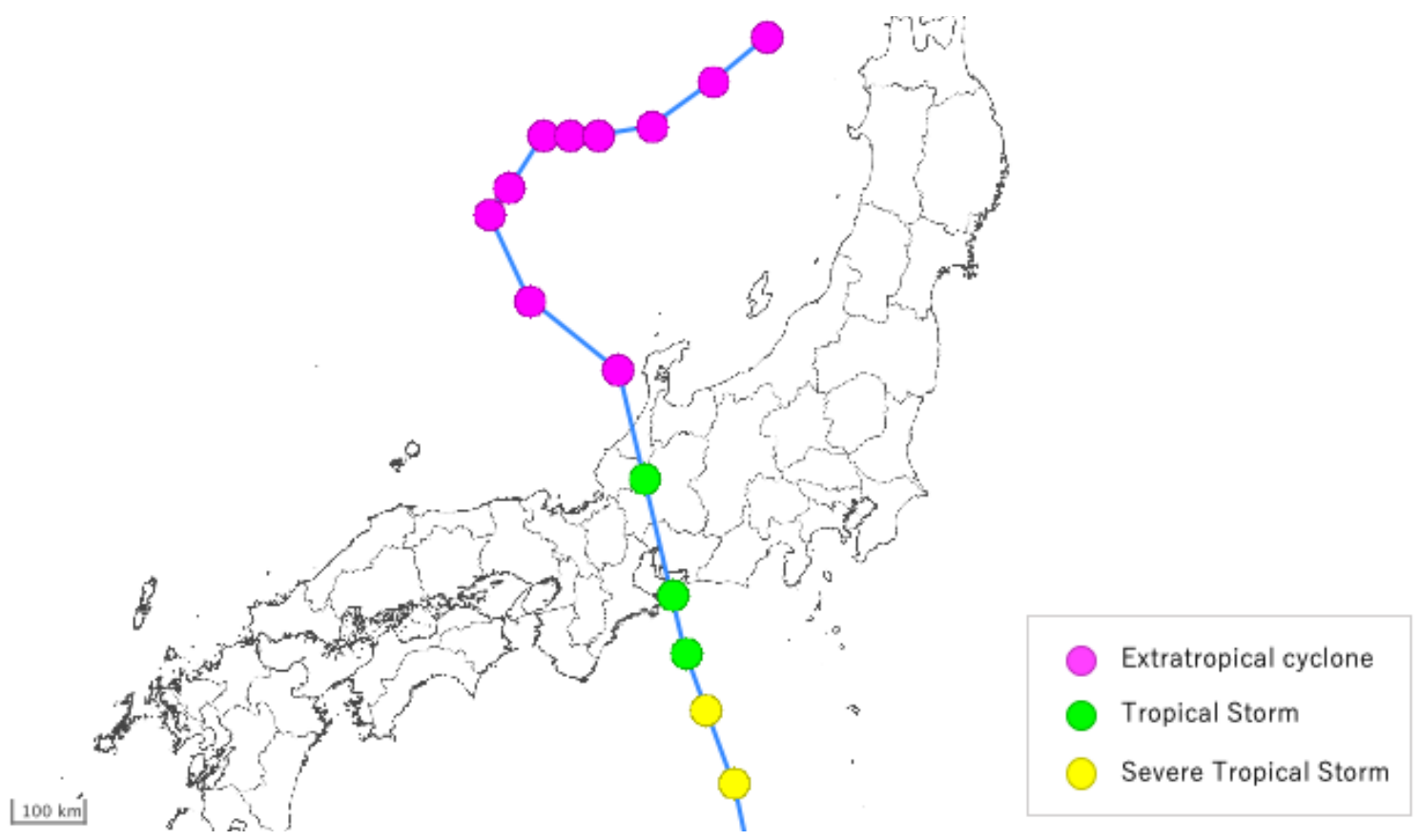

Figure 2: Typhoon Etau caused floods and landslides in many places in the Eastern part of Japan

As a widespread event affecting multiple prefectures at the same time, Typhoon Etau represents a rather unique opportunity to compare disaster response across multiple regions. Comparing separate disasters is difficult as many factors can affect public responses in general such as its temporal scale (e.g., typhoon or localised torrential rain), season (e.g., typhoon season or not), intensity (e.g., strong typhoon or a small depression). Selecting the same phenomenon removes these factors, which are not the focus of this research. As Typhoon Etau caused widespread impacts over the eastern part of Japan, we are able compare 10 Japanese prefectures (see Figure 2).

\subsection{Data cleaning/Geo-location}

Removing numbers, Latin letters, and symbols. Before analysing the text of tweets, all the unnecessary characters were removed. The main topic of a tweet is generally expressed with words, and hence numbers and symbols (e.g., emoji) carry limited meaning for topic modelling (although they can be useful for further analysis). In addition, since Japanese people tend to use only Japanese characters in tweets, all non-Japanese characters were removed, including @mentions and links. 


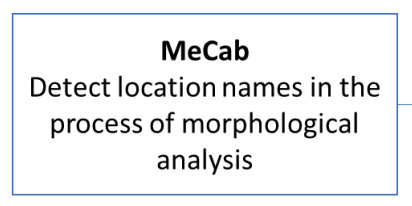

[台風, 洪水, 発生, 安佐南区]

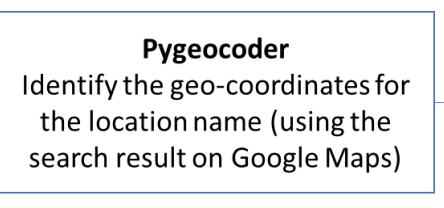

$(34.465857,132.420866)$

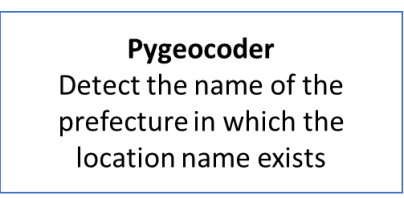

“広島県”

Figure 3: The process flow of location identification method using MeCab and Google Maps Search

Morphological analysis. Unlike most languages, Japanese language does not have spaces between words, and therefore, morphological analysis is needed to separate words [28]. We used MeCab, an open-source morphological analyser in this analysis. MeCab separates text into words and identifies the part-of-speech of each word (e.g., noun, verb, adjective) by analysing the structure of sentences. In general, different parts-ofspeech convey different meanings. Adverbs and adjectives express emotions and sentiments and may therefore be more useful for analysing how people felt in a crisis. Conversely, verbs are often connected to actions and nouns generally indicate the subject / main topic of a message (especially in Japanese). For this reason, only nouns were extracted in this analysis; additional analysis of verbs (actions) could be useful for further study, but the many verb-forms in Japanese can be a source of error. MeCab is the most available and most-used morphological analyser for Japanese, but its vocabulary is not fully comprehensive, and future work may find a dedicated, context-specific dictionary (e..g, one specific to natural disaster-related conversation) offers more precise morphological analysis [32].

Geolocation. We used a keyword-based approach to assign tweets to Japanese prefectures (states). Other approaches such as using only tweets with explicit GPS coordinates or Twitter Place information would limit our coverage too greatly as less than $10 \%$ of tweets have this information [33]. Our approach focuses on the location being discussed in the tweet, which can differ from where the user is physically located as well as their usual home location.

We analysed the text of tweets for location names. In addition to extracting the names of Japanese prefectures, other location names such as the names of cities and towns were identified using MeCab and then assigned to a prefecture using the Google Maps API. The process flow is shown in Figure 3.

The importance of going beyond prefecture names varies by location. In prefectures with a large city, we found tweets were more likely to refer to the city without naming the prefecture. For example, our tweet volume for Kanagawa Prefecture increased $314 \%$ by considering other location names within the prefecture (namely Yokohama City). In contrast, we had only a $28 \%$ increase in the number of tweets assigned to Chiba Prefecture by considering other location names. Keyword-based approaches, however, can lead to false positives [30,33]. We identified only one such false positive in our subsequent data analysis, which is discussed below. Through these processes, the tweets are limited from 5 millions to 50,000. 


\subsection{Topic modelling}

As discussed in Section 1.1, disaster-related agencies would like public responses to shift from awareness to preparation and then to action in a timely manner after the issuance of an advisory, warning, or emergency warning respectively. This research analyses this shift on social media, but such analysis, it should be clear, only measures attention and not public actions. In order to understand how the content of online conversation shifts, we performed topic modelling, specifically with Latent Dirichlet Allocation (LDA), and assigned the topics to one of five categories: awareness, preparation, action, impact, and other. Tweets in the other topic were discarded.

We chose LDA topic modelling as an unsupervised approach as we did not have a strong prior for exactly what topics of conversation would comprise each of these four categories (i.e., a lack of labelled data for supervised approaches) and knowledge that the words relevant to each category would likely differ between locations and change as the disaster progressed. We removed words only occurring once as well as words occurring in more than half of the tweets. The latter are mostly common 'stop words' and other aspects that are too general to assist our analysis. We experimented iteratively with different numbers of topics for LDA until we found topics were internally cohesive and mutually distinct through manual analysis of the 10 most associated words and three tweets most associated with each topic. This process identified 20 topics as an optimal number.

Through the process, we manually assigned each LDA topic to one of our categories. The awareness category included active conversations on the phenomenon that indicated public attention to the hazardous weather conditions. This comprised two LDA topics, one focused on the discussion of the typhoon's intensity, and another discussing the weather forecasts. The preparation category consists of three LDA topics: two focused on general warnings and one on landslide alerts. We use this attention on warning-related information as a signal that people may be getting ready to take action. The action category consists of one LDA topic on evacuation that indicated that people understand the situation and the necessity of evacuation. Finally, the impact category contained topics focused on the damage/impact of the weather without reference to specific actions. The four LDA topics were train disruptions, rivers overflowing their bands, floods, and general disaster impact. LDA topics unrelated to any of these four categories were removed (10 topics).

\section{Results and discussion}

\subsection{Tweet volume, timing, and retweets}

To observe the changes in public attention during the typhoon event, the temporal change in the total number of disaster-related tweets was examined (Figure 4). The graph shows that, while all the prefectures have spikes, the timing of the spikes varies by region. In detail, the volume of tweets peaked first in the most 
south prefectures. Then, volumes peaked in Tokai region, followed by the South Kanto, North Kanto, and Tohoku regions.

Typhoon Etau moved over the eastern part of Japan from the south to the north, and the sequence of spikes corresponds to the movement of the typhoon (see Figure 2). This implies that the volume of content about the typhoon varied with its itensity as experienced in each location.

All prefectures except Tokyo have one period of high-insentity social media activity. Tokyo, in contrast, has three distinct peaks. The first peak at noon of 9 September corresponds to the typhoon approaching to Tokyo. However, the second peak at 10:00am on 11 September is the one false positive mentioned earlier: looking at the content of individual tweets, it seems that most of the tweets posted around at this time mention a river bursting in Osaki City, Miyagi Prefecture, but there is also a Osaki, Tokyo. This is the only naming ambiguity issue that we found in our analysis, but it points to the need for further method development and human verification as mentioned in the methods section. The third and final peak at 6:00am 12 September was because of an earthquake with a medium intensity in Tokyo. We found the tweets in Tokyo included a lot of tweets that mention news on TV.

Meanwhile, retweeting is a function that anyone can instantly share someone else's tweet. This function is a key for rapid and wide information spread but also an unprecedented form of information sharing compared to a traditional information network. This makes researchers keen to investigate the impact of retweeting, for example, about the relationship between spreading rumours and retweets [34, 24].

Figure 5 compares the percentage of all tweets that were retweets among prefectures. Overall, retweets account for around $60 \%$ in most prefectures, which is consistent with findings that approximately 50-60\% of posts on Twitter during the 2011 Japanese earthquake and tsunami were retweets [24]. However, Miyagi, Tochigi, and Ibaraki prefectures show a higher ratio with around $70 \%$. The prefectures with higher ratios were the ones that had particularly devastating damage.

\subsection{Topic prevalence}

Figure 6 compares the component proportion of each topic among prefectures. Looking at the awareness category, all the prefectures show less than 15\%, except Tokyo with 26.9\%. Thus, a larger proportion of the content in Tokyo is simply descriptions of what the phenomenon is like such as strong wind, heavy rain, darkening sky, satellite picture of the typhoon, and so on. Overall, the Preparation category is one of the most popular topics in this analysis. Miyagi shows the highest percentage at $54.8 \%$, followed by Tochigi at $51.4 \%$ and Ibaraki at $49.4 \%$. All of these are the prefectures where emergency warnings were issued. Therefore, there might be a correlation of the prefectures with emergency warning having more online responses, which will be discussed in the next subsection. Action is not popular in any prefecture except Shizuoka Prefecture with $34.3 \%$. Looking at individual tweets in Shizuoka, most are the tweets sharing or retweeting evacuation instruction issued in Hamamatsu City. Finally, all the prefectures show a relatively higher percentage for the 

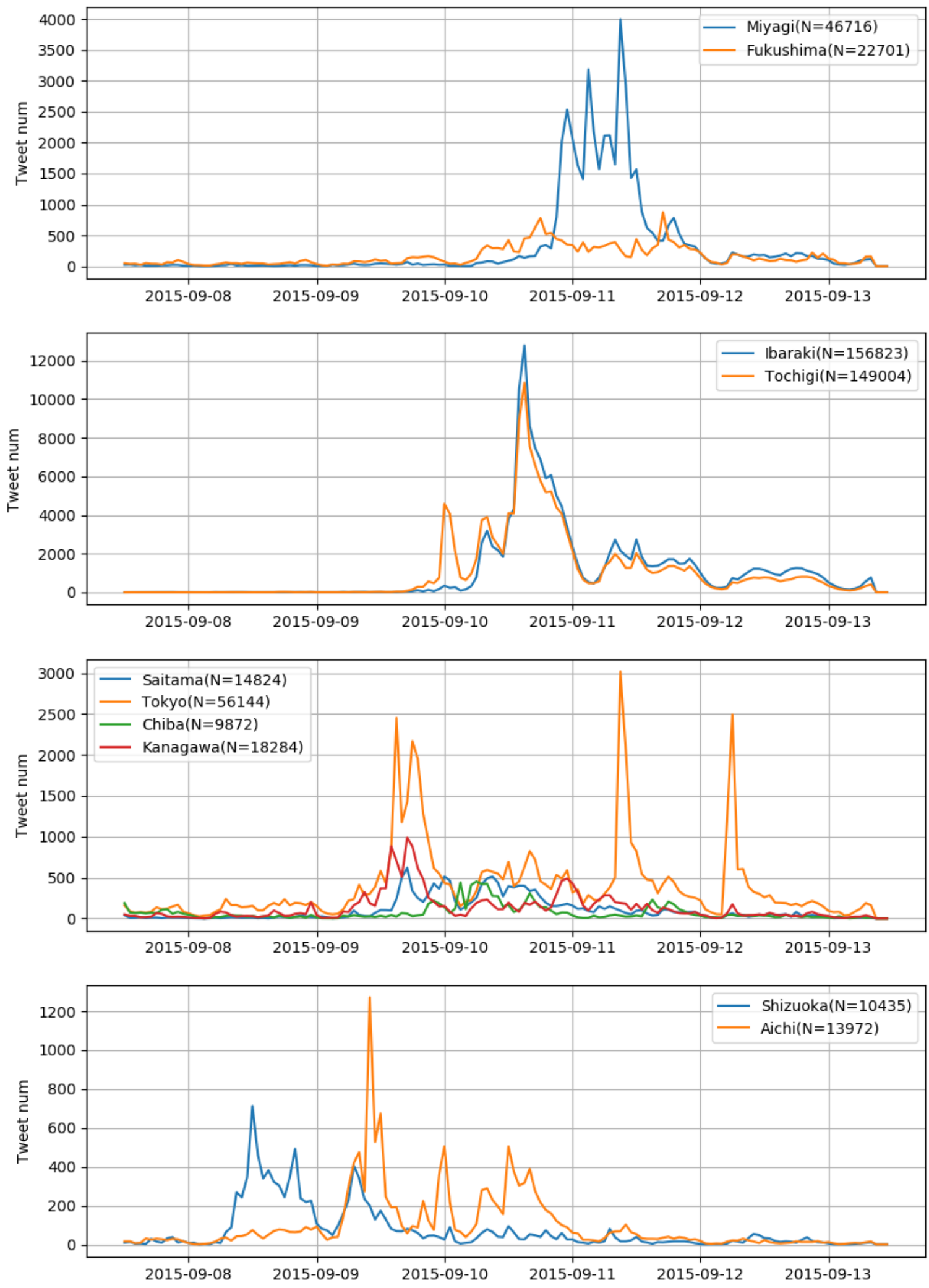

Figure 4: Temporal change in the number of disaster-related tweets in each region (the time of emergency warning issuance: Miyagi 9/11 03:20, Ibraki 9/10 07:45, Tochigi 9/10 00:20) 


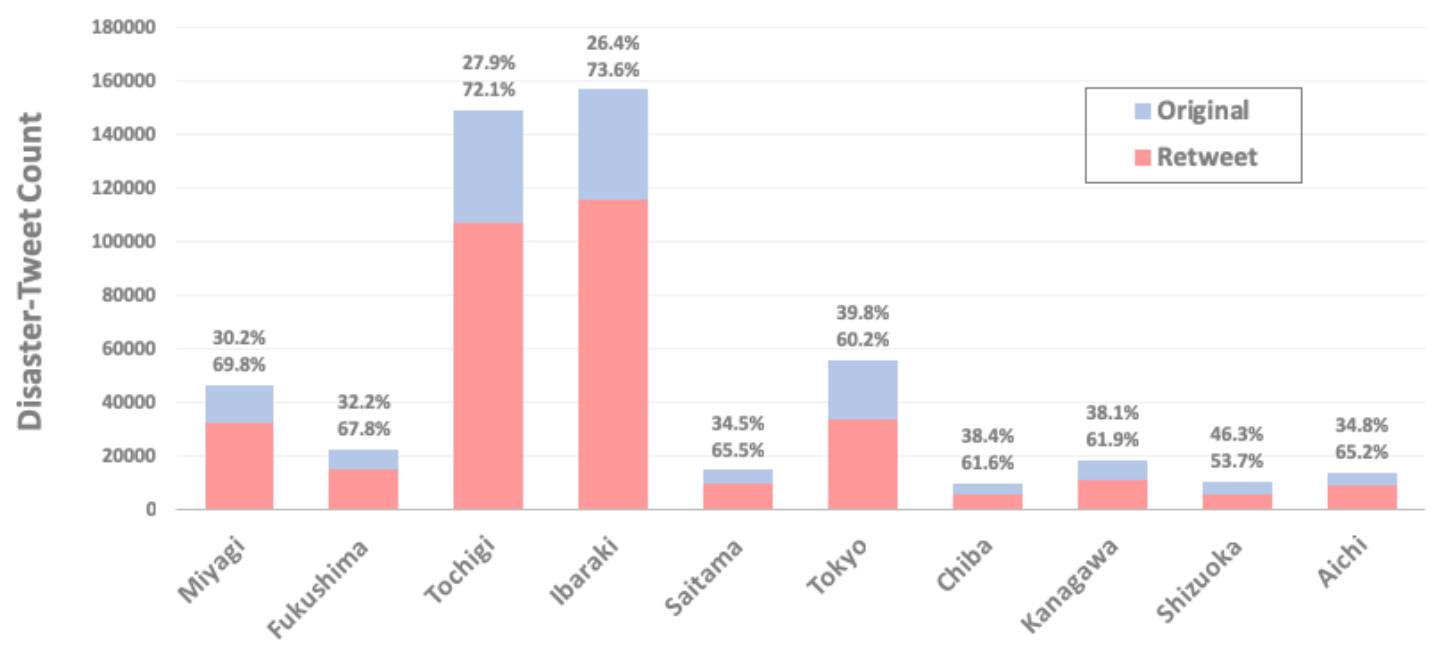

Figure 5: Number of tweets geolocated to each prefecture broken down by original and retweets

Table 1: The result of four separate regression analyses between the component percentage of each topic and emergency warning issuance (0 for no emergency warning, 1 for an emergency warning)

\begin{tabular}{ccccc}
\hline Emergency warning & Phenomenon & Warning & Evacuation & Impact \\
\hline Coefficient & -101.76 & 463.38 & 11.14 & -108.6 \\
p-value & 0.55 & 0.033 & 0.78 & 0.71 \\
R-squared & -0.07 & 0.4 & -0.1 & -0.1 \\
\hline
\end{tabular}

impact category. Overall, half of the disaster-related tweets were about impact.

To quantitatively investigate the effect of emergency warning on each topic, regression analyses were conducted. We ran four models to examine the relationship between an emergency warning issuance and the component percentage of each topic. The result (Table 1) shows that only the warning topic has a statistically significant relationship with the issuance of an emergency warning. The relationship is positive, indicating that prefectures with emergency warning have a higher proportion of the warning topic among disaster-related tweets.

The Japanese government, especially the JMA, has been attempting to educate people with what to do in response to the information provided from the JMA such as warnings, which is the goal of EWSs. However, while most people know the phrase 'emergency warning,' not many understand the intention of emergency warning [35]. As a result, many people think that disasters are someone else's issue and do not take immediate action. The result of this study also supports this idea. Although an increase in the popularity of the warning topic can be seen in the prefectures with emergency warning, no clear change can be seen for the evacuation topic. This implies that people talked about warning issuances but not about the actions 

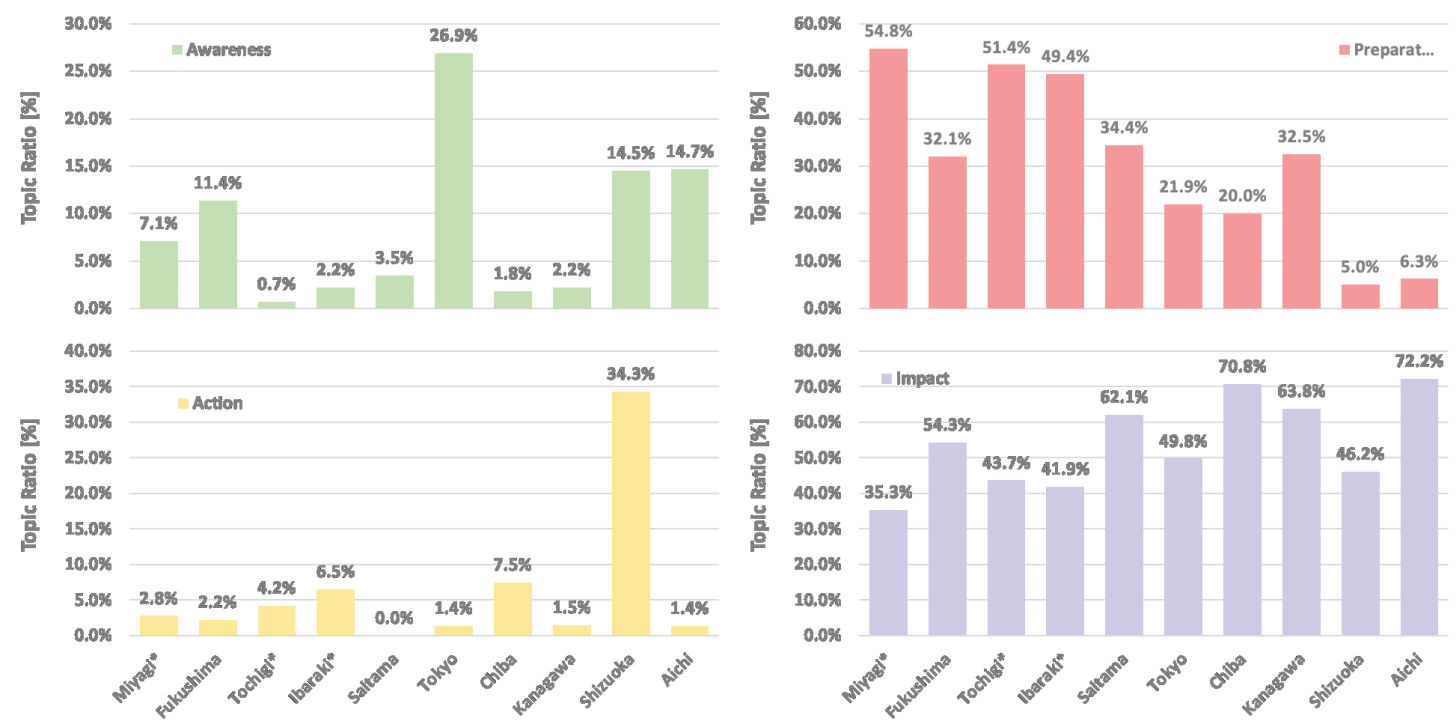

Figure 6: The component proportion of each topic among disaster-related tweets

expected of them. They were perhaps responding more to the catchy and rather unusual phrase 'emergency warning' than engaging with the meaning.

\subsection{Topic detection and tracking (TDT) analysis}

As introduced in Section 1.1, Japan's EWS expects people to shift their attention depending on the stage of disaster. To realise this, a lot of activities have taken place to educate the public with how to respond to each kind of information provided by the government. Although social media has become an important information network, little is known about public responses on social media. In this study, since social media analysis cannot observe actions but attention, the shift of representative disaster-related topics (Phenomenon, Warning, Evacuation, and Impact) in public conversation on Twitter was investigated. Figure 7 compares how these topics changed over time in the three prefectures with emergency warnings. The figure also shows the rainfall and atmospheric pressure. The pressure data tell us how close the typhoon approached; lower pressure means closer. The horizontal colour bar in the graph shows the period during which advisory (yellow), warning (red), and emergency warning (purple) was in effect.

As for the topic on Phenomenon, all the prefectures show a monotonous increase during the event. This indicates that people constantly had kept awareness of the typhoon itself. On the other hand, looking at the warning topic, a sudden rise can be seen in all the prefectures. However, the timing varies among the prefectures: Only Miyagi prefecture shows the rise several hours before the emergency warning was issued, while Tochigi and Ibaraki have the increase at the time of emergency warning issuance. The evacuation topic shows a similar trend to the warning topic. However, while a peak in the warning and evacuation topics 
happened nearly simultaneously in Miyagi, the peak in the evacuation topic followed the peak in the warning topic in Tochigi and Ibaraki. Finally, the impact topic shows a similar change in all the prefectures, while the steepness of the peak is slightly different. Only Ibaraki shows a much steeper increase, compared to the others.

During disaster, people are expected to take an appropriate action depending on the stage of the disaster, starting with "awareness" and shifting to "preparation", and "action". Moreover, this is expected to be done in a timely manner. Looking at the analysis result, it seems that attention generally shifted as expected.

It seems that the public paid attention to warnings and also talked about specific actions, namely evacuation, within these prefectures. While warnings and advisories are relatively frequently issued, JMA holds an emergency press conference when an emergency warning is likely to be issued, and the media deals with it as an exceptional event. This can be an explicit trigger for people to be more attentive. This may be especially important in the case of typhoons, which are long-term phenomena usually taking several days from approaching to landing. In this context, the issuance of the emergency warning can be a clear sign of the imminent situation, leading to more attention to the warning and evacuation topics in this study.

However, the increase of attention on warnings ideally would have happen much earlier than the increase of action category. An emergency warning is issued when a catastrophe is imminent, and JMA warns that action-taking after the issuance of an emergency warning might be too late. In addition, it should take some time to prepare to evacuate. In fact, people are less likely to take an action in response to a prediction of an event that have not happened yet such as tsunami, although people are more likely to take an immediate action for the visible impact like earthquake [36]. Therefore, disaster-related authorities would prefer people are ready to evacuate even before an emergency warning is issued.

\subsection{Response speed}

In addition to analysing the prevalence of different types of tweets, we examined how fast people respond to warnings (via the preparation category) and consider taking action such as evacuation. To analyse this, we calculated the time difference between a heavy rain warning issuance and the peak of the preparation and action categories (Figure 8). In this calculation, we removed the data where the number of tweets was too small (less than 10) and the data where no distinct peak was observed.

Table 2 shows that the period in hours between the warning issuance and the first peak of the warning/evacuation topic. For the warning topic, Miyagi, Shizuoka, and Aichi had less than 10 hours, while other prefectures range from 11.9 to 65 hours. This means that it took some time for people to start talking about

warnings after being issued. Only Ibaraki has a value less than zero, which means that people started talking about warnings before a warning was issued. However, this could be because a warning and emergency warning were issued at the same time in Ibaraki due to a sudden change in the weather conditions. Before issuing an emergency warning, news media broadcasted the possibility of issuing an emergency warning. This 

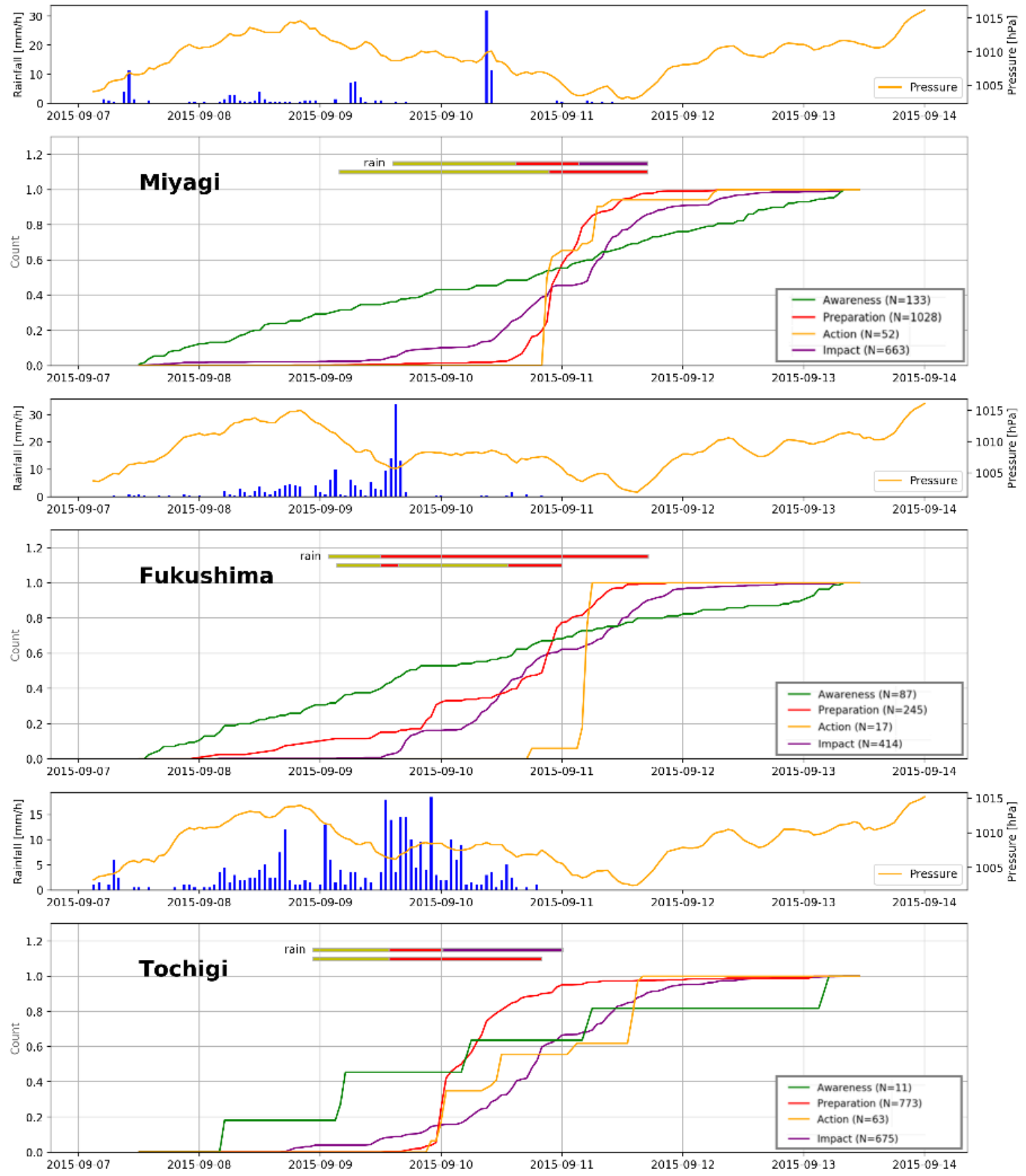

Figure 7: An example of the temporal change in the popularity of the four categories during the 2015 typhoon event 

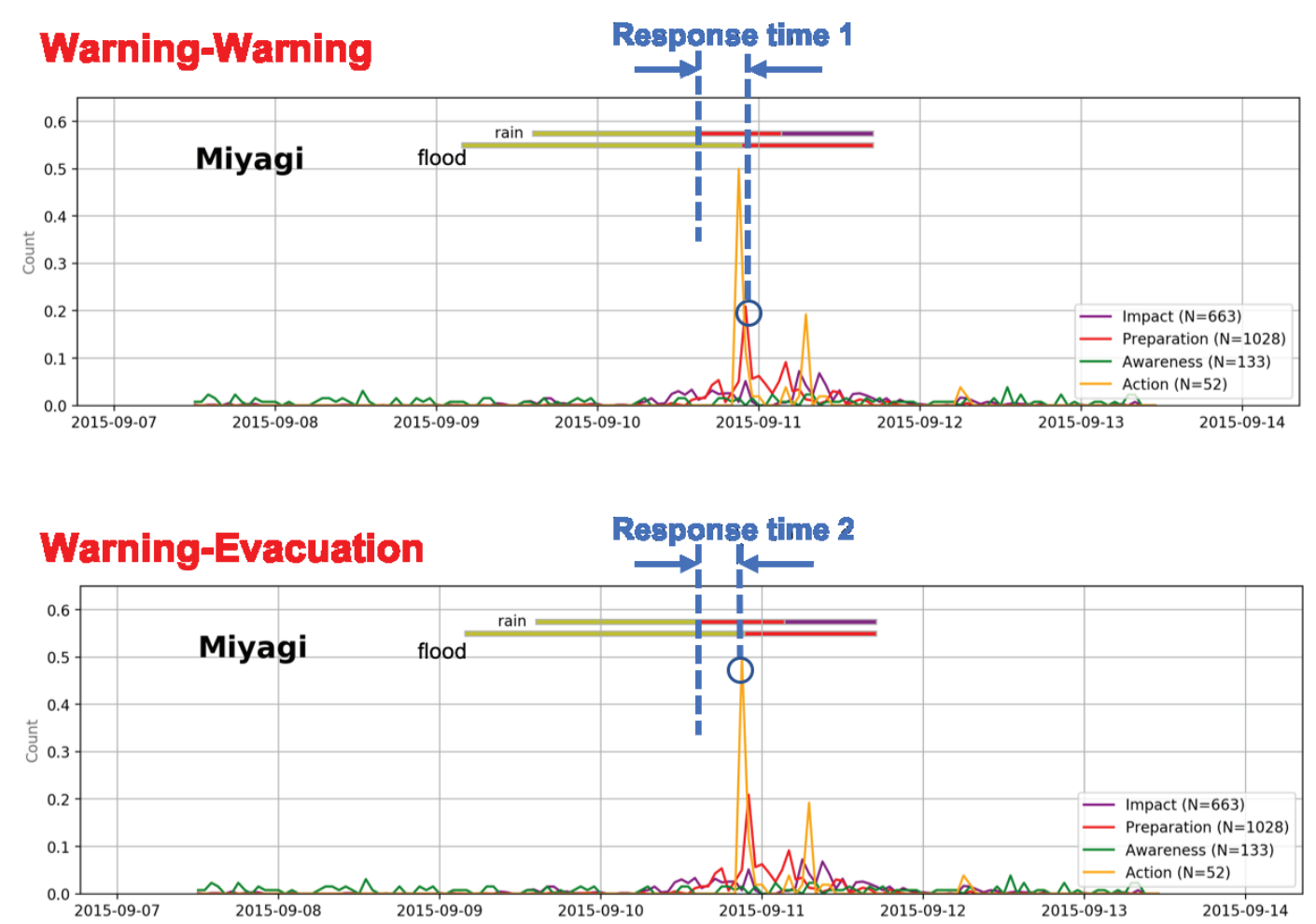

Figure 8: How to calculate response time 
Table 2: Response time (the period between warning issuance and the first peak of the warning and evacuation topics)

\begin{tabular}{ccc}
\hline & Warning (hours) & Evacuation (hours) \\
\hline Miyagi* & 7.3 & 6.3 \\
Fukushima & 33.1 & 41.1 \\
Tochigi* & 10.4 & 11.4 \\
Ibaraki* & -0.8 & 3.3 \\
Saitama & 29.2 & - \\
Tokyo & 29.6 & 36.6 \\
Chiba & 11.9 & 14.9 \\
Kanagawa & 65.0 & - \\
Shizuoka & 9.8 & 1.8 \\
Aichi & 3.2 & - \\
\hline
\end{tabular}

*The prefectures with an emergency warning

may have made people more aware of the warnings even before a warning and an emergency warning was issued. On the other hand, for the action category, only Miyagi, Ibaraki, and Shizuoka had values less than 10 hours. The response time for the preparation category is smaller than for the action category in all the prefectures except Miyagi and Shizuoka. Qualitatively, it seems that prefectures with an emergency warning tend to have a quicker response, although there are some exceptions such as Shizuoka and Aichi.

This study attempted to find a relationship between emergency warning and how quickly public attention shifted to the warning and evacuation topics after the warning issuance. However, no statistically significant relationship was observed. This regression analysis used only 10 samples (prefectures). Therefore, more prefectures perhaps with more disaster cases can be added for future work.

\section{Conclusions}

In the last decade, the potential of social media to enhance DRR capacity in Japan has been discussed in various ways. However, little is known about the use of social media during disasters, although most research has focused on before- and after-disaster cases such as the recovery phase where public conversation can assist governments in identifying issues needing to be addressed. Recently, the ideal form of warnings for natural disasters has been changing significantly, from a scientific insight to a result-oriented comprehensive system, which is called EWSs. To discuss the feasibility of using social media as part of EWSs, this study attempted to investigate online public responses to warnings using the case of Typhoon Etau and the Kanto-Tohoku Heavy Rains in Japan. 
We found from a regression analysis that there was a statistically significant correlation between the component proportion of the preparation category and issuance of an emergency warning, but not for the component proportion of the action category. This implies that public action does not shift to evacuation, supporting offline findings that many people tend to hesitate to take action even in an emergency situation.

On the other hand, EWSs require people to respond to government information in a timely manner: Attention, Preparation, and Action. Our analysis of public attention shows that this shift seems to happen on social media. To help people do this shift more quickly, the Japanese Government started issuing emergency warnings. However, we did not find a statistically significant relationship between the issuance of an emergency warning and the response time for either the preparation or action category. Nonetheless, this question should be considered further with a deeper analysis.

In this analysis, we used only one disaster case with 10 prefectures. Nonetheless, we made several noteworthy observations. Social media data seem a useful complement to survey data - each has its own biases; so, the two are probably best used together. We found Japanese Twitter users were focused on awareness throughout the disaster, but that there was significant delay between the issuance of a warning and its discussion online. Emergency warnings were talked about more quickly online, perhaps because they are rarer. Such emergency warnings also often moved online discussion forward to the preparation stage. In general, retweeting is very common during this disaster: retweeting evacuation instructions is one prominent example.

For future work, other cases should be investigated. Public responses are expected to be dependent on many other factors, ranging from disaster-related (e.g., intensity, length, size, disaster type) to nondisaster-related factors (e.g., regional socioeconomic differences, daytime/night). People might respond more quickly or in greater volume to a more significant event. People might be more aware of a disaster on a weekend compared to a weekday. Identifying the environmental factors that affect the public responses and comparing them should give useful insights to understand how people respond to natural disasters. Analysing cases beyond Japan will be important as well. This paper has served as a pilot case study showing the value of examining social media data during disasters as a complimentary view to traditional survey studies on disaster response. Moreover, network analysis and other methods instead of manual analyses we used should be investigated to understand what further insights may be available for disaster-related authorities. These methods might tackle questions such as identifying who plays an important role in crisis information dissemination and how information propagates during a crisis. In addition to a comprehensive management for EWSs, these understandings can help authorities develop more specific strategies for the use of social media such as reaching the public more quickly and widely than traditional communication channels, enhancing public-central information circulation, and collecting more granular disaster information. 


\section{Acknowledgements}

We would like to thank Professor Masashi Toyoda for his support as well as our reviewers for their helpful comments.

\section{References}

[1] M. Ushiyama, 日本の風水害人的被害の経年変化に関する基礎的研究, 土木学会論文集 B1(水工学) 73 (4) (2017) 1369-1374.

[2] C. C. Hood, H. Z. Margetts, The tools of government in the digital age, Macmillan International Higher Education, 2007.

[3] H. Z. Margetts, T. Escher, Governing from the centre? comparing the nodality of digital governmentsdoi:http://dx.doi.org/10.2139/ssrn.1755762.

[4] World Meteorological Organization, Wmo guidelines on multi-hazard impact-based forecast and warning services, Vol. 1150, 2015.

URL https://www.wmo.int/pages/prog/www/DPFS/Meetings/ET-OWFPS_Montreal2016/documents/ WMOGuidelinesonMulti-hazardImpact-basedForecastandWarningServices.pdf

[5] S. Geertman, J. Ferreira, R. Goodspeed, J. Stillwell, Introduction to 'planning support systems and smart cities', in: S. Geertman, J. Ferreira, Jr., R. Goodspeed, J. Stillwell (Eds.), Planning Support Systems and Smart Cities, Springer International Publishing, 2015, pp. 1-17. doi:10.1007/978-3-319-18368-81.

[6] M. N. Siying JIN1, Satoshi TSUTSUI, An analysis of the community disaster management power and ict - community disaster management plan at sophia statia, yokosuka seaside new town, 第 32 回情報通 信学会大会予稿.

[7] R. R. Rao, J. Eisenberg, T. Schmitt, Improving Disaster Management: The Role of IT in Mitigation, Preparedness, Response, and Recovery. doi:10.17226/11824.

[8] S. Goel, A. Anderson, J. Hofman, D. J. Watts, The structural virality of online diffusion, Management Science 62 (1) (2015) 180-196.

[9] H. Fukunaga, Masaki, K. Kawano, 台風による大雨と初の特別警報（危機の情報はどう伝わったか）. 放 送研究と調査 $2014,2014$.

URL https://www.nhk.or.jp/bunken/summary/research/report/2014_01/20140101.pdf

[10] R. Goolsby, Social media as crisis platform: The future of community maps/crisis maps, ACM Transactions on Intelligent Systems and Technology (TIST) 1 (1) (2010) 7. 
[11] I. F. of Red Cross, Community early warning systems: guiding principles.

[12] R. Mukhtar, Review of national multi-hazard early warning system plan of pakistan in context with sendai framework for disaster risk reduction, Procedia engineering 212 (2018) 206-213.

[13] C. Garcia, C. J. Fearnley, Evaluating critical links in early warning systems for natural hazards, Environmental Hazards 11 (2) (2012) 123-137.

[14] M.-A. Baudoin, T. Wolde-Georgis, Disaster risk reduction efforts in the greater horn of africa, International Journal of Disaster Risk Science 6 (1) (2015) 49-61.

[15] M. Ushiyama, 平成 30 年 7 月豪雨時の災害情報に関するアンケート (2018 年 7 月実施). URL http://www.disaster-i.net/disaster/20180706/20180803report-2.pdf

[16] H. F. Weisberg, The Total Survey Error Approach: A Guide to the New Science of Survey Research, The University of Chicago Press, 2005.

[17] D. Roger, V. Tsirkunov, Implementing hazard early warning systems, Vol. 11, 2011. URL https://www.preventionweb.net/files/24259_implementingearlywarningsystems1108.pdf

[18] S. Teramae, An introduction to meteorological policy science, Vol. 9, pp. 35-50.

[19] D. Linders, From e-government to we-government: Defining a typology for citizen coproduction in the age of social media, Government Information Quarterly 29 (4) (2012) 446-454.

[20] T. Escher, H. Margetts, V. Petricek, I. Cox, Governing from the centre? comparing the nodality of digital governments, in: Annual Meeting of the American Political Science Association, Vol. 31, 2006.

[21] J. N. Sutton, E. S. Spiro, B. Johnson, S. M. Fitzhugh, M. Greczek, C. T. Butts, Connected communications: network structures of official communications in a technological disaster, in: Proceedings of the 9th International ISCRAM Conference, 2012.

[22] J. Sutton, E. S. Spiro, B. Johnson, S. Fitzhugh, B. Gibson, C. T. Butts, Warning tweets: Serial transmission of messages during the warning phase of a disaster event, Information, Communication \& Society 17 (6) (2014) 765-787.

[23] O. Mauroner, A. Heudorfer, Social media in disaster management: How social media impact the work of volunteer groups and aid organisations in disaster preparation and response, International Journal of Emergency Management 12 (2) (2016) 196-217.

[24] A. Miura, F. Toriumi, M. Komori, N. Matsumura, K. Hiraishi, Relationship between emotion and diffusion of disaster information on social media: Case study on 2011 tohoku earthquake, 人工知能学会 論文誌 31 (1). 
[25] H. Margetts, P. John, S. Hale, T. Yasseri, Political turbulence: How social media shape collective action, Princeton University Press, 2015.

[26] S. A. Hale, P. John, H. Margetts, T. Yasseri, How digital design shapes political participation: A natural experiment with social information, PLOS ONE 13 (4) (2018) 1-20. doi:10.1371/journal.pone.0196068. URL https://doi.org/10.1371/journal.pone.0196068

[27] P. Cihon, T. Yasseri, A biased review of biases in twitter studies on political collective action, Frontiers in Physics 4 (2016) 34.

[28] S. A. Hale, Global connectivity, information diffusion, and the role of multilingual users in user-generated content platforms, Ph.D. thesis, Oxford University, UK (2014).

[29] J. Bright, The social news gap: How news reading and news sharing diverge, Journal of Communication 66 (3) (2016) 343-365.

[30] C. Castillo, Big crisis data: Social media in disasters and time-critical situations, Cambridge University Press, 2016.

[31] H. Jin, M. Toyoda, N. Yoshinaga, Can cross-lingual information cascades be predicted on twitter?, in: International Conference on Social Informatics, Springer, 2017, pp. 457-472.

[32] Y. Sakamaki, E. Kamei, A case study of text mining tweet data: How to correct information from the affected area in a large-scale disaster, J Jpn Ind Manage Assoc 39 (65) (2014) 39-50.

URL https://www.jstage.jst.go.jp/article/jima/65/1/65_39/_pdf

[33] M. Graham, S. A. Hale, D. Gaffney, Where in the world are you? geolocation and language identification in Twitter, The Professional Geographer 66 (4) (2014) 568-578. doi:10.1080/00330124.2014.907699.

[34] Y. Murayama, M. Mukai, H. Nishioka, Y. Saito, A model for decision making in retweet which caused spreading of false rumor in emergencies, マルチメディア、分散、協調とモバイルシンポジウム.

[35] M. Ushiyama, An analysis of understanding of residents in flood inundation area for heavy rainfall emergency warning, J.JSNDS 33.

[36] K. T. . K. S. Katada T, Kodama M, 住民の避難行動にみる津波防災の現状と課題, 土木学会論文集 789 (11) (2015) 93-104. 